\section{Commentary: Postoperative interventricular septal hematoma-Never say never}

\author{
Harold M. Burkhart, MD, Jess L. Thompson, MD, and \\ Klayton W. Buckley, CCP
}

Interventricular septal hematoma (IVSH) is rarely reported in association with congenital cardiac surgical repair and is more commonly related to cardiac trauma or myocardial infarction in the adult cardiac patient. When linked to congenital cardiac surgery, the few cases reported are usually in conjunction with a perimembranous ventricular septal defect (VSD) repair. Although the mechanism for IVSH is not clear, the leading theory involves injury to the septal perforating artery during suture placement in the VSD repair. ${ }^{1}$ This vessel is at risk when suturing the patch to the anterior rim of the perimembranous VSD. Vascular injury with anticoagulation may result in continued bleeding with IVSH formation. An enlarging hematoma may lead to cardiac dysfunction, outflow tract obstruction, and cardiac arrhythmias. Fortunately, most cases of IVSH have not required further intervention, responding to expectant management ${ }^{2}$; however, reports of prolonged intubation times, longer intensive care stays, and aneurysmal left ventricular changes exist. ${ }^{3}$ Given that there are currently fewer than 30 cases of IVSH reported in the literature, it may be reasonable to think that most pediatric cardiac surgeons will never have to deal with this complication.

In this issue of the Journal, Jegatheeswaran and colleagues ${ }^{4}$ describe their experience with 12 patients during a 12-year period who had IVSH occur after VSD repair. Although the review included a period of 37 years, there were no cases of IVSH found before 2005. All the patients underwent VSD repair, with the most common diagnosis being tetralogy of Fallot. There were 4 deaths,

\footnotetext{
From the Division of Cardiovascular and Thoracic Surgery, University of Oklahoma Health Sciences Center, Oklahoma City, Okla.

Disclosures: Authors have nothing to disclose with regard to commercial support.

Received for publication Oct 14, 2019; revisions received Oct 14, 2019; accepted for publication Oct 15, 2019; available ahead of print Nov 19, 2019.

Address for reprints: Harold M. Burkhart, MD, Division of Cardiovascular and Thoracic Surgery, University of Oklahoma Health Sciences Center, PO Box 26901, WP-2230, Oklahoma City, OK 73105 (E-mail: Harold-burkhart@ouhsc. edu).

J Thorac Cardiovasc Surg 2020;159:1943-4

0022-5223/\$36.00

Copyright (C) 2019 by The American Association for Thoracic Surgery

https://doi.org/10.1016/j.jtcvs.2019.10.084
}

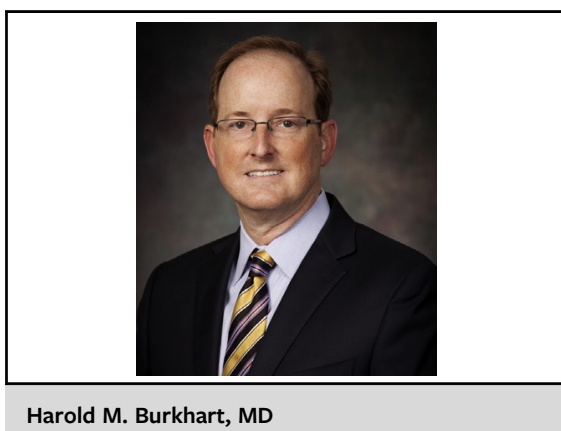

\begin{abstract}
CENTRAL MESSAGE
Postoperative interventricular septal hematoma seldom occurs and can be successfully managed expectantly or, if necessary, with extracorporeal membrane oxygenation support.
\end{abstract}

with an overall survival of $67 \%$. Five of the patients were in unstable condition and required extracorporeal membrane oxygenation (ECMO) support, with 2 surviving $(40 \%)$. The obvious value of this article is that it nearly doubles the number of postoperative IVSH cases in the literature, which may aid us in understanding this complication and its management. Drawing on their larger, single-center experience, Jegatheeswaran and colleagues ${ }^{4}$ judge that younger patients with lower weights are particularly at risk, presumably as a result of decreased visualization during the repair. Importantly, they also demonstrate that ECMO can be utilized for patients in unstable condition, and, with tailored anticoagulation, septal hematoma expansion can be avoided and similar survival to that reported in the Extracorporeal Life Support Registry (ELSO) database can be expected. $^{5}$

There are some limitations to the study because of the low number of patients, spanning several years and surgeons. The mechanism for the IVSH may not be simply secondary to a septal perforator artery injury. Two-thirds of the patients had tetralogy of Fallot, and one must consider what role muscle resection in the right ventricular outflow tract may play in IVSH development. In addition, although Jegatheeswaran and colleagues ${ }^{4}$ have shown it possible to manage patients with IVSH who are in unstable condition on 
ECMO support, it would have been helpful to provide a more specific anticoagulation algorithm.

In summary, postoperative IVSH is a rare surgical complication that fortunately can be managed conservatively most of the time. For the patient in unstable condition, it appears that ECMO support is a viable management option. Given that Jegatheeswaran and colleagues ${ }^{4}$ have seen this complication about once a year for the last 12 years of the study period, one has to wonder whether it is rare or just underdiagnosed. The real value in the article may very well be that it brings attention to a rare complication with which we all might deal at least once in our careers.

\section{References}

1. Yoneyama F, Matsubara M, Sakamoto H, Hiramatsu Y. Interventricular septal hematoma associated with congenital heart surgery: a case report and literature review. J Thorac Cardiovasc Surg. 2017;153:e55-7.

2. Jensen R, Burg P, Anderson C, Garabedian C, Garabedian H, Siwek L, et al. Postoperative ventricular septal hematoma: natural history of two pediatric cases. $J$ Thorac Cardiovasc Surg. 2007;133:1651-2.

3. Yamazawa H, Takeda A, Nakajima H, Tachibana T, Aoki M. Interventricular septal hematoma following repair of a ventricular septal defect. J Card Surg. 2017;32:390-3.

4. Jegatheeswaran A, Cohen MS, Gaynor JW, Mascio CE, Spray TL, Fuller S. Extracorporeal membrane oxygenation as a novel management strategy for interventricular septal hematoma following ventricular septal defect repair. J Thorac Cardiovasc Surg. 2020;159:1936-40.

5. ELSO. Extracorporeal Life Support Registry Report, International Summary. 2019. Available at: https://www.elso.org/Registry/Statistics/International Summary.aspx. Accessed September 27, 2019. 